\title{
KAJIAN BIBLIKA TENTANG BERPUASA BERDASARKAN YESAYA 58:1-12 DAN IMPLIKASINYA BAGI ORANG PERCAYA MASA KINI
}

\author{
Reza Mensis, Yunus D. A. Laukapitang
}

\begin{abstract}
Abstrak
Tujuan penulisan skripsi ini adalah menjelaskan secara Alkitabiah tentang konsep berpuasa berdasarkan Yesaya 58:1-12. Adapun metode yang digunakan oleh penulis adalah metode kualitatif yaitu metode penelitian kepustakaan yaitu membaca buku-buku yang relevan, tafsiran-tafsiran dan menyelidiki kitab yang berkaitan dengan pembahasan konsep berpuasa dalam kitab Yesaya 58:1-12. Selain itu penulis juga menggunakan analisis konteks, analisis struktur, dan analisis teks dengan mencari makna dari setiap kata-kata penting dalam nas. Dari hasil penelitian ini maka penulis menarik beberapa kesimpulan. Pertama, Nabi Yesaya diperintahkan Allah untuk mengecam dan menegur setiap kesalahan yang bangsa Israel perbuat semasa mereka menjalankan ibadah puasa mereka. Kedua, berpuasa merupakan sikap respons orang percaya dalam mereka merendahkan diri dan meninggalkan hal-hal keduniawian. Ketiga, dalam menjalankan ibadah puasa harus sesuai dengan apa yang Allah kehendaki. Berpuasa juga merupakan salah satu disiplin rohani kepada Allah. Dalam menjalankan kegiatan puasa seseorang harus membawa damai sejahtera dan melayani orang lain. Berpuasa juga meningkatkan kesalehan individual seseorang dan kesalehan sosial seseorang.
\end{abstract}

Kata-kata Kunci: Bangsa Israel, Berpuasa, Orang Percaya, Yesaya.

\section{Pendahuluan}

\section{Latar Belakang Masalah}

Berpuasa bukan suatu hal yang asing lagi bagi orang Kristen. Berpuasa bagi kebanyakan orang dipahami hanya sebagai kegiatan spiritual di mana orang yang melakukannya tidak makan dan minum selama waktu yang ditentukan. Banyak juga yang berpendapat bahwa puasa ialah seseorang pantang terhadap makan.

Andrew Brake dalam bukunya, Spritual Formation, mengatakan puasa adalah sahabat terbaik dari doa di mana berpuasa menunjukkan tentang urgensi dan keseriusan doa-doa seseorang. ${ }^{1}$ Dalam berpuasa seseorang fokus kepada kegiatan-kegiatan spiritual yang merujuk kepada Allah. Memusatkan diri dengan hal-hal yang rohani dan tidak menyibukkan diri dengan hal-hal duniawi. Adalah lebih baik jika orang-orang percaya berpuasa dan berdoa sebelum mengambil keputusan yang sangat penting juga ketika timbul masalah di dalam gereja. ${ }^{2}$

\footnotetext{
${ }^{1}$ Andrew Brake, Spritual Formation (Bandung: Kalam Hidup, 2014), 134.

${ }^{2}$ Ibid., 135 .
} 
Richard Foster dalam bukunya yang terkenal, Celebration of Discipline mengatakan bahwa berpuasa tidak bisa lepas dari tuntunan kuasa Allah, dalam bukunya mengatakan:

Fasting must forever centre on God. It must be God-initiated and God-ordained. Like the prophetess Anna, we need to be 'worshipping with fasting. Every other purpose must be subservient to God. ${ }^{3}$

Pemahaman Richard Foster akan berpuasa juga bukan hanya sekadar berpuasa tetapi bagaimana seseorang melakukan hal yang lebih diluar dari berpuasa seperti beribadah, melakukan penyembahan karena berpuasa dikendalikan oleh Allah dan atas otoritas Allah. Pusat dari seseorang berpuasa ialah Allah di mana Ia yang memberikan kuasa dan berkat atas puasa yang dilakukan.

Berpuasa menunjukkan pertobatan dan dukacita seseorang atas dosa. Dalam berpuasa yang disertai air mata atas doa dosa pribadi, dosa bangsa, Allah mendengar doadoa seperti itu. ${ }^{4}$ Bukan hanya berfokus kepada keadaan tidak makan dan minum pada saat berpuasa dan juga tindakan dalam berpuasa melainkan dalam berpuasa pengampunan akan dialami bagi mereka yang serius dalam berpuasa yang disertai dengan doa yang serius.

Tuhan Yesus memberikan contoh ti mana Dia tidak lepas dari berdoa dan berpuasa, bahkan ketika akan memulai pelayanannya Dia terlebih dahulu berpuasa empat puluh hari tanpa makan (Lukas 4:1-2). Yesus pun memerhatikan dan melakukan akan hal ini, Dia merasakan lapar yang juga dirasakan oleh kebiasaan orang. Ada juga beberapa tokoh Alkitab yang memerhatikan puasa ini diantaranya ada Musa yang berpuasa selama empat puluh hari. Musa, melakukan puasa 40 hari 40 malam dalam ia berpuasa ia tidak makan dan tidak minum, ia memilih bersama-sama dengan Tuhan dengan tanggung jawab besar yang diberikan Allah kepada dia (Keluaran 34:28).

Kesaksian dari Raja Daud yang diceritakan dalam Kitab Perjanjian Lama bahwa Daud pun berpuasa (Mazmur 109:24; 2 Samuel 12:16). Daud berdoa kepada Tuhan agar anaknya masih diberikan hidup, demi anak ia tidak makan dan semalaman berbaring diatas tanah tetapi Tuhan bermaksud lain dan Daud tidak menyalahkan Tuhan (2 Sam 12:16-22). Dalam sejarah cerita perjalanan Perjanjian Lama, dapat ditemukan lagi ada banyak para tokoh yang melakukan puasa di antaranya Ratu Ester yang begitu memerhatikan akan esensi dari berpuasa dia menyuruh semua orang yang Yahudi yang berada di Susan untuk berpuasa dan tidak hanya mereka yang berpuasa. Ester sendiri ikut turut dalam melakukan puasa untuk menghadap raja ia tidak makan dan tidak minum selama tiga hari (Est 4:16). Ester dan Mordekhai berpuasa untuk menyelamatkan umat Israel dari gerakan pemusnahan yang direncanakan oleh Haman yang kemudian terjadi setelah dilakukan puasa berhari-hari keadaan menjadi terbalik di mana umat Israel selamat dan juga menghantarkan Mordekhai menjadi Perdana Menteri dan menghantarkan Haman ke tiang gantungan yang dirancangnya sendiri. ${ }^{5}$

Daniel yang berdoa, berpuasa, dan mengenakan kain kabung. Dalam ia menjalankan puasanya, ia menaikkan doa kepada Allah dan mengaku segala dosanya baik dosa pribadinya maupun dosa bangsa Israel, dapat dilihat bagaimana Daniel dalam menjalankan puasanya bukan berfokus kepada diri sendiri tetapi kepada penyangkalan diri dan mendoakan orang lain bentuk puasa yang sejati (Dan 9:3-19).

\footnotetext{
${ }^{3}$ Richard Foster, Celebration of Discipline: A Path to Spritual Life (San Fransisco: Harper Collins, 1988), 54

${ }^{4}$ Brake, 137.

${ }^{5}$ Emang, "Puasa Yang Alkitabiah," diakses 10 Agustus 2019, https://www.academia.edu/34690202/Puasa_yang_Alkitabiah?auto=download.
} 
Niniwe, ketika Allah berfirman bahwa Niniwe akan ditunggangbalikkan dalam 40 hari. Orang-orang Niniwe berpuasa, tidak hanya orang-orangnya tetapi juga segala ternak, dengan berpuasa dan berkabung, tidak makan, tidak minum dan tidak berbuat jahat (Yunus 3:7). Kemudian Allah melihat apa yang mereka lakukan dan Allah melihat bahwa benarbenar mereka melakukannya dengan benar dan Allah pun menyesal telah merencanakan malapetaka kepada mereka (Yunus 3:10).

Bagi bangsa Israel mempunyai kebiasaan berpuasa pada hari pendamaian untuk mentahirkan bangsa Israel dengan cara merendahkan diri dan tidak melakukan suatu pekerjaan (Im 16:29-31; Bil 29:7). Dalam Kitab Zakaria, di mana orang Israel sesudah pembuangan harus melakukan 4 kali puasa dalam setahun (Zak 8:19). Dalam tradisi Perjanjian Lama juga puasa dalam prakteknya adalah wujud di mana seseorang memperlihatkan atau menggambarkan bahwa ia sedang berduka dan berdoa kepada Tuhan (1 Sam 31:13; Neh 1:4). Dalam artian keseluruhan atas apa yang dijelaskan oleh Perjanjian Lama mengenai berpusa merupakan tradisi atau kebiasaan masyarakat yang beragama dalam menjaga hubungan agar tetap baik dengan Allah.

Kemudian bagaimana dengan bangsa Israel dalam Yesaya 58:1-12 mereka berpuasa dengan merendahkan diri tetapi Allah tidak mengindahkan perbuatan mereka. Mereka berpikir bahwa Allah pasti memberikan perhatian besar kepada mereka, dan mengakui bahwa Allah berutang pada mereka atas ibadah-ibadah mereka. ${ }^{6}$ Padahal mereka sudah merendahkan diri dan berkabung tetapi Allah masih saja tidak mengindahkan perbuatan mereka (ayat 5). Alasan utama puasa dan doa-doa mereka tidak diterima oleh Allah yaitu karena mereka melakukannya atas motivasi yang tidak baik, bukan kepada Allah melainkan kepada diri mereka sendiri. Mereka berpuasa tetapi mereka bersikeras terhadap dosa-dosa mereka dan tiap-tiap dari mereka tidak berbalik dari kehidupan jahat mereka seperti orang-orang Niniwe. ${ }^{7}$ Hal-hal yang demikian yang Allah tidak kehendaki bagi mereka dalam mereka menjalankan ibadah puasa mereka. Bangsa Israel tidak memahami ketika mereka berpuasa harus merendahkan diri tetapi nyata-nyatanya mereka melanggar dan mereka berpuasa tidak sesuai dengan aturan awal.

Wycliffe mengungkapkan tentang kesalehan Israel yang hanya pura-pura dengan ibadah dan puasa yang mereka jalankan, mereka hanya untuk memperlihatkan kepada semua orang bagaimana kesalehan hidup mereka dengan dibarengi pelanggaran dan kefasikan, ketaatan kepada agama tidak cukup jika umat Tuhan tidak hidup saleh dan taat kepada hukum Allah. Ada janji Tuhan bagi umat Tuhan jikalau mereka menjalankan puasa mereka dengan benar yaitu janji keselamatan dan memulihkan keadaan mereka. ${ }^{8}$

Matthew Henry menjelaskan di mana Nabi Yesaya diperbaharui untuk menegur orang-orang berdosa di Sion di mana dengan ibadah-ibadah lahiriah yang bangsa Israel laksanakan membuat mereka terlindung dari teguran Allah khususnya kepada puasa yang mereka lakukan, mereka memegahkan puasa mereka yang terus mereka jalankan di Babel dan selama beberapa waktu setelah mereka kembali ke negeri mereka sendiri. Puasa yang mereka jalankan tidak serta merta mendatangkan damai sejahtera karena tidak dilakukan dengan benar dan tidak sesuai dengan apa yang Allah kehendaki. ${ }^{9}$

Bangsa Israel dalam menjalani kegiatan keagamaan mereka merujuk kepada kepentingan diri sendiri, di mana dikatakan oleh Wycliffe dan Matthew Henry bahwa mereka hanya ingin orang-orang memerhatikan kehidupan mereka yang disebut-sebut sebagai orang saleh yang dibarengi dengan sifat kefasikan dan melakukan kebiasaan-

\footnotetext{
${ }^{6}$ Matthew Henry, Tafsiran Matthew Henry: Kitab Yesaya 40-66 (Surabaya: Momentum, 2016) 1126.

${ }^{7}$ Ibid., 1127.

${ }^{8}$ Pfeiffer dan Harrison, The Wycliffe Bible Commentary (Malang: Gandum Mas, 2014), 545-546.

${ }^{9}$ Henry, 1121.
} 
kebiasaan ibadah yang bersifat lahiriah. Suatu alasan yang jelas bagaimana Allah tidak mengindahkan segala perbuatan mereka yang penuh kefasikan dan lahiriah.

Bagaimana dengan orang-orang percaya saat ini yang biasanya mereka berpuasa tetapi masih hidup di dalam dosa. Apakah mereka menerima pengampunan dari Allah atas puasa yang mereka jalani. Kebanyakan dari orang-orang percaya berpuasa tidak memerhatikan bagaimana kehidupannya dengan dosa. Dosa yang sering diperbuat menjadi suatu kebiasaan dan terkadang dianggap sepele ketika menjalankan puasa. Orang-orang kurang melihat kepada diri mereka di mana dosa harus diselesaikan dengan Allah dan kebanyakan orang hanya sekadar berpuasa tanpa memerhatikan apa yang menjadi natur dari manusia yaitu dosa mereka. Ketika seseorang juga dalam berpuasa mereka melupakan akan hubungan sosial dengan orang lain, mereka melaksanakan puasa tetapi mengabaikan orang lain. Hanya berfokus kepada diri sendiri bahkan gereja pun demikian dalam mereka menjalankan program doa dan puasa mereka di gereja hanya berfokus kepada kegiatan doa dan pujian tanpa tindakan langsung kepada orang-orang yang diluar gereja.

Oleh sebab itu, berdasarkan latar belakang masalah di atas penulis membahas ini sebagai acuan bagi orang-orang percaya masa kini untuk tidak hanya sekadar berpuasa dalam sekadar ikut berpartisipasi dalam kegiatan-kegiatan spiritual melainkan memahami makna dan tujuan dari puasa itu sendiri, bagaimana Allah turut bekerja dalam puasa yang dilakukan dengan benar dan bagaimana seseorang hidup kudus dan melepaskan pengampunan terhadap orang lain. Berpuasa tidak hanya soal pantang makan dan minum, berdoa dan beribadah melainkan berpuasa juga seseorang tidak hidup dalam kompromi kepada Allah juga manusia dan memiliki hubungan yang baik dengan semua orang. Jadi berdasarkan penjelasan latar belakang di atas maka penulis merasa terdorong untuk mengangkat masalah tersebut sebagai skripsi. Oleh karena itu judul yang diangkat oleh penulis adalah KAJIAN BIBLIKA TENTANG BERPUASA BERDASARKAN YESAYA 58:1-12 DAN IMPLIKASINYA BAGI ORANG PERCAYA.

\section{Pokok Masalah}

Dengan melihat latar belakang masalah di atas, maka yang menjadi pokok masalah dalam skripsi ini adalah :

Pertama, apa konsep berpuasa berdasarkan Yesaya 58:1-12 ?

Kedua, apa implikasi berpuasa berdasarkan Yesaya 58:1-12 bagi kehidupan orang percaya?

\section{Tujuan Penelitian}

Berdasarkan pokok masalah di atas maka tujuan penulisan ini yaitu:

Pertama, untuk menjelaskan konsep berpuasa yang dikendaki oleh Allah berdasarkan Yesaya 58:1-12.

Kedua, untuk menjelaskan implikasi teologis dan praktis berpuasa bagi kehidupan orang percaya masa kini berdasarkan Yesaya 58:1-12.

\section{Manfaat Penelitian}

Adapun manfaat dari penulisan skripsi ini adalah:

Pertama, skripsi ini dapat bermanfaat bagi para pembaca dan menambah wawasan bagi penulis serta pembaca dan sekolah-sekolah teologi. 
Kedua, orang percaya dapat mengerti tentang berpuasa yang dikehendaki oleh Allah berdasarkan Yesaya 58:1-12.

Ketiga, untuk memenuhi persyaratan akademik dalam mencapai gelar sarjana teologia di Sekolah Tinggi Filsafat Jaffray Makassar.

\section{Metode Penelitian}

Adapun metode penulisan yang dipakai dalam penulisan skripsi ini ialah metode kualitatif, yaitu metode penelitian kepustakaan (Library Research) yaitu membaca bukubuku yang relevan, tafsiran-tafsiran dan menyelidiki kitab yang berkaitan dengan pembahasan skripsi ini. ${ }^{10}$ Selain itu, penulis juga mencari dan menggunakan internet, pengumpulan jurnal-jurnal.

\section{Batasan Penelitian}

Dalam penulisan ini, penulis memberikan batasan tentang berpuasa berdasarkan Yesaya 58:1-12. Adapun referensi lain dari tafsiran-tafsiran yang berkembang mengenai pokok bahasan penulisan juga acuan serta ide-ide dalam membantu penulisan skripsi ini.

\section{Sistematika Penulisan}

Untuk memudahkan pembaca, maka penulis memberikan uraian singkat dalam penulisan skripsi ini dengan sistematika sebagai berikut:

Bab I, merupakan pendahuluan yang berisikan tentang latar belakang masalah, pokok masalah, tujuan penelitian, manfaat penelitian, metode penelitian, batasan penelitian, dan sistematika penulisan.

Bab II, membahas latar belakang Kitab Yesaya di antaranya penulis Kitab Yesaya, garis besar Kitab Yesaya, tujuan penulisan Kitab Yesaya, tema utama Kitab Yesaya, keunikan Kitab Yesaya, waktu dan tempat penulisan.

Bab III, membahas eksegesis tentang berpuasa berdasarkan Yesaya 58:1-12 yang terdiri dari genre Yesaya 58:1-12, analisis konteks Yesaya 58:1-12, analisis struktur Yesaya 58:1-12, analisis nas Yesaya 58:1-12, penjelasan nas Yesaya 58:1-12, Seruan kepada umat Allah (Ayat 1-3b), berpuasa yang tidak dikehendaki Allah yaitu masih tetap mengurus urusan (ay.3), mendesak-desak semua buruhmu (ay. 3b), berpuasa sambil berbantah dan berkelahi (ay.4), memukul dengan tinju dengan tidak semena-mena (ay.4b), mengadakan hari merendahkan diri (ay.5), menundukkan kepala seperti gelagah (ay.5), membentangkan kain karung dan abu sebagai lapik tidur (ay.5b). Adapun yang akan dibahas juga ialah berpuasa yang dikehendaki Allah yaitu membuka belenggu-belenggu kelaliman (ay.6), melepaskan tali-tali kuk (ay.6), memerdekakan orang yang teraniaya (ay.6), mematahkan setiap kuk (ay.6), memecah-mecah roti bagi orang yang lapar (ay.7), membawa ke rumahmu orang yang miskin yang tak punya rumah (ay.7), memberi pakaian kepada orang telanjang (ay.7), tidak menyembunyikan diri terhadap saudaramu sendiri (ay.7). Juga membahas hasil dari berpuasa yang benar yaitu terang akan merekah seperti fajar dan luka akan pulih dengan segera (ay.8), kebenaran menjadi barisan depan dan kemuliaan Tuhan barisan belakang (ay.8), pada saat memanggil Tuhan akan menjawab dan pada saat minta tolong Ia akan berkata: Ini Aku. (ay.9), terang akan terbit dalam gelap dan kegelapan akan rembang tengah hari (ay.10), Tuhan akan menuntun senantiasa (ay.11),

\footnotetext{
${ }^{10}$ Rajo, 144; Delvy dan Laukapitang, 103.
} 
memuaskan hati di tanah kering (ay.11), membaharui kekuatanmu (ay.11), Engkau akan seperti taman yang diairi dengan baik (ay.11), membangun reruntuhan yang sudah berabad-abad dan akan memperbaiki dasar yang diletakkan oleh banyak keturunan (ay.12), Akan disebutkan 'yang memperbaiki tembok yang angus.' (ay.12b), 'Yang membetulkan jalan supaya tempat itu dapat dihuni.' (ay.12c).

Bab IV, menjelaskan implikasi teologis dan implikasi praktis berpuasa berdasarkan Yesaya 58:1-12 dalam kehidupan orang percaya. Implikasi teologis berpuasa adalah berpuasa itu kehendak Allah. Implikasi praktis yaitu berpuasa salah satu disiplin rohani kepada Allah, berpuasa membawa damai sejahtera, berpuasa dengan hidup saling melayani dan berpuasa meningkatkan kesalehan individu dan kesalehan sosial.

$\mathrm{Bab} \mathrm{V}$, membahas kesimpulan dan saran-saran.

\section{Kesimpulan}

Berdasarkan pembahasan tentang berpuasa berdasarkan Yesaya 58:1-12, maka dapat ditarik beberapa kesimpulan yaitu:

Pertama, Nabi Yesaya diperintahkan Allah untuk mengecam dan menegur setiap kesalahan yang bangsa Israel perbuat semasa mereka menjalankan ibadah puasa mereka. Bahwa bangsa Israel dalam menjalankan ibadah puasa mereka, mereka sambil berbantahbantah dan membuat kejahatan terhadap orang-orang miskin dan orang yang tertindas.

Kedua, Allah menginginkan bahwa bangsa Israel harus berbalik dari kejahatannya yaitu membawa damai dan hidup dalam kesalehan sosial untuk mereka bisa menerima berkat dan pemulihan dari Tuhan. Allah menjanjikan ketika mereka hidup benar dalam menjalankan puasa mereka, Yerusalem akan dipulihkan dan sukacita terbit atas mereka.

Ketiga, berpuasa mengajarkan bagaimana diri seseorang berfokus kepada Tuhan dan menyangkal diri terhadap segala kenikmatan dunia. Berpuasa bukan hanya soal berpantang dari makanan dan minuman tetapi juga bagaimana dalam menjalankan puasa, kehidupan secara pribadi sendiri diberkati dan orang lain juga diberkati. Berpuasa juga merupakan sikap respons orang percaya dalam mereka merendahkan diri dan meninggalkan hal-hal keduniawian.

Keempat, implikasi teologis berpuasa ialah berpuasa itu kehendak Allah, Allah menghendaki agar orang percaya dalam menjalankan puasa tidak sementara hidup dalam kebejatan moral dan sosial yang merugikan orang lain dan sesama.

Kelima, implikasi praktis dalam berpuasa ialah berpuasa salah satu disiplin rohani kepada Allah bahwa kedisiplinan seseorang terhadap puasa akan membuat dirinya menjadi pribadi yang dapat diandalkan oleh Tuhan, pemulihan dan berkat Tuhan akan di alami bagi mereka yang melaksanakannya. Bentuk seseorang yang memiliki hubungan yang baik dan sadar akan Tuhan ialah membangun dalam dirinya kedisiplinan untuk berpuasa. Berpuasa membawa damai sejahtera ialah melepaskan beban-beban orang yang tertindas, melepaskan hal-hal yang mengikat kepada orang-orang bawahan dan melepaskan orangorang yang dianiaya, membiarkan orang lain merasakan kebebasan tanpa kuk yang membebani orang-orang miskin atau hamba-hamba. Kemudian, berpuasa dengan hidup saling melayani yaitu membagi-bagikan makanan kepada orang yang lapar, apa yang mereka miliki mereka harus membagi-bagikannya kepada orang yang membutuhkan. Memperhatikan kondisi orang-orang yang tidak punya rumah untuk dibawa bersama-sama masuk ke dalam rumah dalam mendapatkan tempat yang layak untuk ditinggali. Memerhatikan kebutuhan akan pakaian bagi mereka yang tidak memiliki pakaian atau mereka yang tidak mempunyai pakaian tetapi sudah tidak layak pakai hendaklah umat Allah memperhatikan akan hal itu. Pelayanan diakonia transformatif dalam membawa 
perubahan sosial dan ekonomi orang-orang. Berpuasa meningkatkan kesalehan individu dan kesalehan sosial di mana harus ditingkatkan bersama-sama ketika dalam berpuasa, berpuasa kepada Allah dan turut berpartisipasi dalam memperhatikan kehidupan orang lain.

\section{Saran-Saran}

Adapun saran-saran yang dapat disampaikan kepada pembaca dan orang percaya masa kini adalah:

Pertama, bagi gereja perlu menyadari bahwa dalam berpuasa tidak hanya berfokus kepada diri sendiri tetapi juga kepada orang-orang disekitar. Gereja dalam menjalankan program puasa perlu menyadari akan kehadiran orang lain juga bagaimana gereja melayani orang-orang diluar dari gereja.

Kedua, orang percaya masa kini harus hidup dan menyadari akan hidup yang membawa perubahan karena orang percaya saat ini masih kurang menyadari akan apa yang seharusnya mereka lakukan, hanya ikut arus yang sudah ada seperti dalam halnya berpuasa. Dalam berpuasa bukan hanya berfokus kepada diri sendiri tetapi bagaimana kehidupan seseorang membawa dampak perubahan yang baik untuk orang lain seperti melayani orang lain, tidak hidup dalam dendam dan amarah serta tidak menyakiti orang lain. Penulis menyarankan agar kehidupan orang percaya tidak hidup otoriter atau individualism.

Ketiga, orang percaya dan gereja saat ini penulis sarankan agar tidak hanya berfokus kepada peningkatan kesalehan individual tetapi juga mengembangkan kesalehan sosial agar orang-orang disekitar dapat merasakan damai sejahtera dari Allah. Kesalehan individual dan kesalehan sosial harus berimbang berjalan bersama-sama dalam memuliakan Allah.

Keempat, tulisan ini masih jauh dari kesempurnaan. Penafsiran yang terdapat dalam tulisan ini masih bisa dikembangkan lebih lanjut. Kajian biblika tentang berpuasa dapat diteliti lebih dalam dengan melihat latar belakang konteks budaya orang Israel.

Kelima, untuk menghasilkan tulisan yang berisikan penafsiran yang lebih mendalam dan berkualitas, maka dapat menggunakan strategi pembimbingan kepada mahasiswa sejak dini yaitu sejak mahasiswa akhir akan memilih eksegesis yang akan dilakukan sehingga dalam pemilihan judul, mahasiswa sudah mendapatkan bimbingan yang terarah sehingga memungkinkan mahasiswa tersebut dapat menghasilkan tulisan yang lebih berkualitas lagi.

\section{Kepustakaan}

Alkitab. Jakarta: Lembaga Alkitab Indonesia, 2012

Baker, David L. Mari Mengenal Perjanjian Lama. Jakarta: BPK Gunung Mulia, 1992.

Baker, D. L., S. M. Siahaan, dan A. A. Sitompul. Pengantar Bahasa Ibrani. Jakarta: BPK Gunung Mulia, 2016.

Balchin, John, Peter Cotterell, Mary Evans, Gilbert Kirby, Peggy Knight, dan Derek Tidball. Intisari Alkitab Perjanjian Lama. Jakarta: Persekutuan Pembaca Alkitab, 2005.

Barth, M. C. Tafsiran Alkitab Kitab Yesaya Pasal 56-66. Jakarta: BPK Gunung Mulia, 1996.

BibleWorks Version 7 (versi 7).

Brake, Andrew. Spritual Formation. Bandung: Kalam Hidup, 2014. 
Browing, W. R. F. Kamus Alkitab. Jakarta: BPK Gunung Mulia, 2007.

Bullock, C. Hassell. Kitab Nabi-Nabi Perjanjian Lama. Malang: Gandum Mas, 2002.

Conner, Kevin J., dan Ken Malmin. Interpreting The Scriptures Hermeneutik. Malang: Gandum Mas, 2004.

e-Sword.

Emang. "Puasa Yang Alkitabiah." Diakses 10 Agustus 2019. https://www.academia.edu/34690202/Puasa_yang_Alkitabiah?auto=download.

Ericha, Novelia. "Kesalehan Sosial dan Kesalehan Individu.” Diakses 22 Juli 2019. https://www.academia.edu/25902961/Kesalehan_Sosial_dan_Kesalehan_Individu.

Foster, Richard. Celebration of Discipline: A Path to Spritual Life. San Fransisco: Harper Collins, 1988.

Fransisca, Delvy dan Yunus D. A. Laukapitang. "Kepemimpinan Yosia Berdasarkan Kitab 2 Tawarikh 34:1-7 dan Implikasi Bagi Kepemimpinan Pemuda di Gereja." Jurnal Ilmu Teologi dan Pendidikan Agama Kristen 1, no. 2 (Desember 2020): 103-122. https://ojs.sttjaffray.ac.id/jitpk/article/view/508/pdf_7.

Green, Denis. Pembimbing Pada Pengantar Perjanjian Lama. Malang: BPK Gunung Mulia, 1992.

Handoko, Yakub Tri. "Berpuasa (Matius 6:16-18).' Diakses 10 Agustus 2019. http://rec.or.id/article_680_Berpuasa-(Matius-6:16-18).

Hamlin, E. John. A Guide To Isaiah 40-66. London: SPCK, 1979

Henry, Matthew. Tafsiran Matthew Henry: Kitab Yesaya 40-66. Surabaya: Momentum, 2016.

Hill, Andrew E. dan John H. Walton. Survei Perjanjian Lama. Malang: Gandum Mas, 1996.

Houser, Charles dan Scott Tunseth (editor). Alkitab Edisi Studi. Jakarta: Lembaga Alkitab Indonesia, 2010.

Maiaweng, Peniel C. D. Diktat Hermeneutik6ßerjanjian Lama. Makassar: Sekolah Tinggi Theologia Jaffray Makassar, 2016. Belum dipublikasikan.

Ningrum, Vernanda Dwi Ayu. "Model Diakonia Transformatif Pelayanan Yayasan Sosial Bagi Masyarakat Di Sekitar Gereja Mawar Sharon.” Diakses 22 Juli 2019. https://www.academia.edu/37809315/Model_Diakonia_Transformatif_Pelayanan_ Yayasan_Sosial_Bagi_Masyarakat_Di_Sekitar_Gereja_Mawar_Sharon.

Panjaitan, B. H., C. Z. Panjaitan. Konkordansi Topikal. Jakarta: Surya Mahardika, 2007.

Pfeiffer, Charles F. dan Everett F. Harrison. The Wycliffe Bible Commentary. Malang: Gandum Mas, 2014.

Prince, Derek. Doa dan Puasa Menentukan Masa Depan. Jakarta: Yayasan Pekabaran Injil Immanuel, 1995.

Rajo, Gabriel Yobert. "Dosa Yerusalem dalam Yehezkiel 22:1-31: Kajian Biblika dan Implikasi Praktis." Jurnal Ilmu Teologi dan Pendidikan Agama Kristen 1, no. 2 (Desember 2020): 144-162. https://ojs.sttjaffray.ac.id/jitpk/article/view/518.

Ryken, Leland, James C. Wilhoit, Tremper Longman III (editor). Kamus Gambaran Alkitab. Surabaya: Momentum, 2011.

Smith, David Rusworth. Kuasa Puasa: Disiplin Yang Terabaikan. Bandung: Kalam Hidup, 2004.

Sutanto, Hasan. Hermeneutik: Prinsip dan Merode Penafsiran Alkitab. Malang: Literatur SAAT, 2015.

Stamps, Donald C. (editor). Alkitab Penuntun Hidup Berkelimpahan. Malang: Gandum Mas, 2015. 
Teschner, Achim. Rangkaian Visi Mutiara Kitab Yesaya. Jakarta: Yayasan Komunikasi Bina Kasih, 2002.

Webb, Barry G. The Message Of Isaiah. USA: Inter-Varsity Press, 1997.

"Yes 58:1-12 - Tafsiran/Catatan - Alkitab SABDA.” Diakses 20 Juli 2019.

https://alkitab.sabda.org/commentary.php?passage=Yes\%2058:1-12. 